\title{
Development of adenocarcinoma at the remnant intrapancreatic cyst 16 years after resection of the choledochal cyst
}

\author{
Soo Young Oh, Jae Hyun Kwon, and Shin Hwang
}

\author{
Department of Surgery, Asan Medical Center, University of Ulsan College of Medicine, Seoul, Korea
}

\begin{abstract}
One of the main reasons to resect choledochal cyst (CC) is to prevent malignant transformation. After resection of $\mathrm{CC}$, the remnant intrapancreatic bile duct is no longer exposed to the enzymatic insult from pancreatic juice activated by the bile. Thus theoretically, the risk of malignant transformation disappears. We present a case showing development of adenocarcinoma from the remnant CC 16 years after resection of CC. A 43 year-old female patient underwent resection of type I CC 16 years ago, leaving a small remnant portion of CC as it was located deep within the pancreas close to the anomalous union of the pancreatobiliary duct. Four years later, intrahepatic ducts were dilated due to anastomotic stricture of the hepaticojejunostomy, which was resolved after repeated balloon dilatation. On follow-up examination at postoperative 16 years, a mass within the pancreas head was identified. As the mass was identified as adenocarcinoma on biopsy, pylorus-preserving pancreatoduodenectomy was performed. Pathologic examination showed a $3.5 \mathrm{~cm}$-sized moderately differentiated adenocarcinoma arising from the remnant $\mathrm{CC}$, with no lymph node metastasis. The patient recovered uneventfully, and is currently undergoing adjuvant chemotherapy. This case indicates that remnant CC can undergo malignant transformation. Therefore, complete resection of CC coupled with life-long follow-up is emphasized. (Ann Hepatobiliary Pancreat Surg 2019;23:192-196)
\end{abstract}

Key Words: Malignant transformation; Incomplete resection; Anomalous union of pancreatobiliary duct

\section{INTRODUCTION}

Resection of choledochal cyst (CC) with anomalous union of pancreatobiliary duct (AUPBD) is almost always indicated because of its malignant potential. It is well known that persistent reflux of bile juice into the biliary tract through AUPBD causes recurrent inflammation of the bile duct, leading to hyperplasia and metaplasia of the epithelium which predispose to malignant transformation., ${ }^{1,2}$ Therefore, resection of $\mathrm{CC}$ eliminates risk of malignant transformation as the remnant bile is no longer exposed to enzymatic insult from pancreatic juice, theoretically. However, in clinical practice, such risk of malignant transformation does not disappear completely.

We herein present a case of adenocarcinoma that arose from the remnant $\mathrm{CC}$ that was located deep in the pancreas 16 years after resection.

\section{CASE}

A 43 year-old female patient who had undergone resection of type I CC (Fig. 1) 16 years ago at the age of 27 years was admitted for work-up and surgery for biliary malignancy. At the time of initial surgery for $\mathrm{CC}$ resection and hepaticojejunostomy (HJ), a small remnant portion of $\mathrm{CC}$ was left to prevent pancreatic duct injury as it was located deep within the pancreas close to the AUPBD.

Two years later after operation, follow-up computed tomography (CT) revealed a small polypoid lesion in the distal common bile duct stump (Fig. 2). Endoscopic retrograde cholangiopancreatography (ERCP) biopsy of the lesion showed chronic inflammation with fibrosis.

Four years later after the operation, she was admitted with pancreatitis, and stricture at the common pancreatobiliary channel was found in follow-up ERCP. Balloon dilation was performed to treat the stricture.

Received: April 11, 2019; Revised: April 15, 2019; Accepted: April 20, 2019

Corresponding author: Shin Hwang

Department of Surgery, Asan Medical Center, University of Ulsan College of Medicine, 88 Olympic-ro 43-gil, Songpa-gu, Seoul 05505, Korea Tel: +82-2-3010-3930, Fax: +82-2-3010-6701, E-mail: shwang@amc.seoul.kr

Copyright (C) 2019 by The Korean Association of Hepato-Biliary-Pancreatic Surgery

This is an Open Access article distributed under the terms of the Creative Commons Attribution Non-Commercial License (http://creativecommons.org/ licenses/by-nc/4.0) which permits unrestricted non-commercial use, distribution, and reproduction in any medium, provided the original work is properly cited. Annals of Hepato-Biliary-Pancreatic Surgery • pISSN: 2508-5778 - eISSN: 2508-5859 

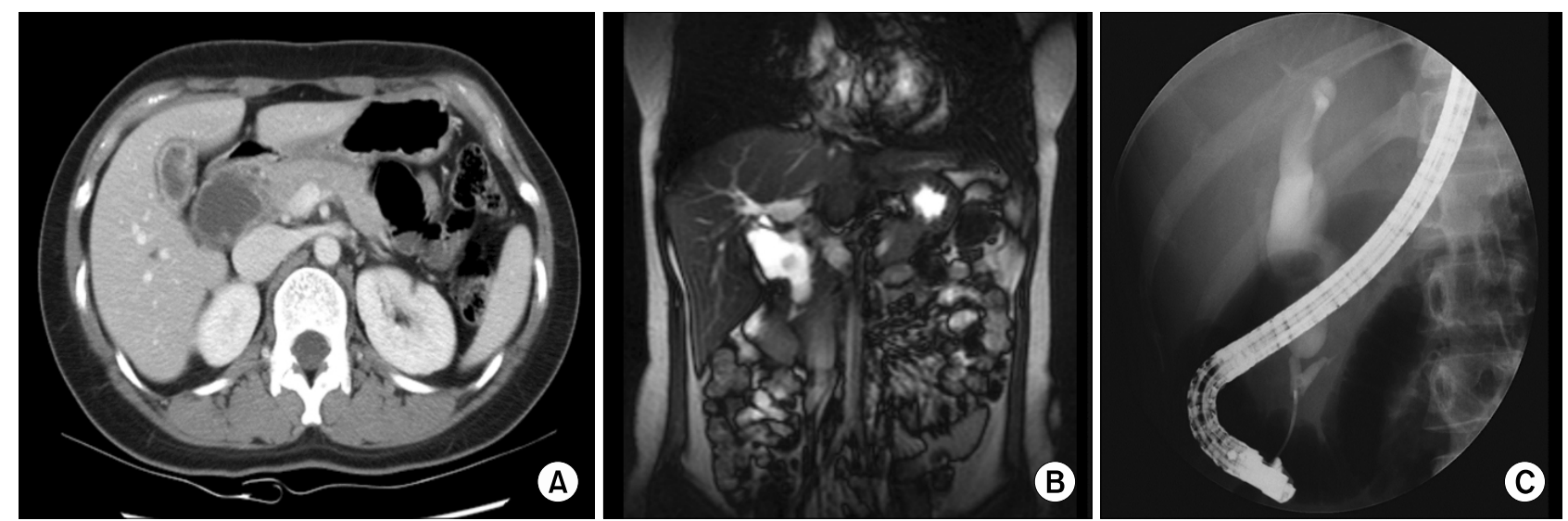

Fig. 1. Preoperative radiologic findings. (A) Fusiform dilatation of the intra- and extrahepatic ducts is identified. (B) Magnetic resonance cholangiopancreatography finding suggests choledochal cyst with anomalous union of pancreatobiliary duct and stone formation in the dilated extrahepatic duct. (C) Endoscopic retrograde cholangiopancreatography finding shows choledochal cyst with anomalous union of pancreatobiliary duct of a long common channel.
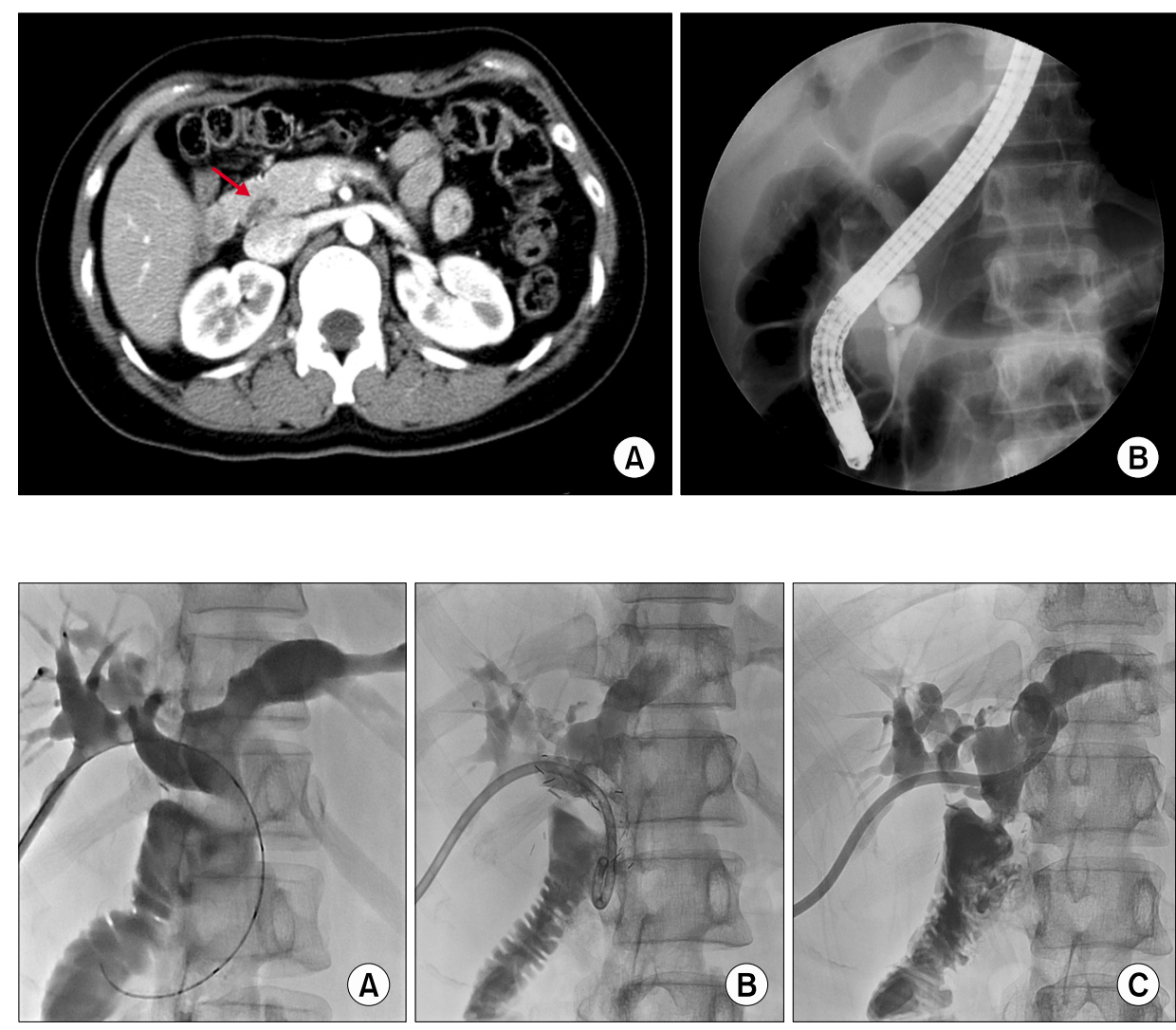

Fig. 3. Radiologic findings taken 10 years after choledochal cyst excision. (A) Percutaneous transhepatic biliary drainage (PTBD) tubogram shows nearly complete occlusion of the hepaticojejunostomy. (B) Balloon dilatation was performed with crossover of a PTBD tube. (C) Hepaticojejunostomy stricture was resolved after stent insertion.
Six to 12 years after the operation, she had 3 more episodes of cholangitis with intrahepatic duct stricture and common hepatic duct stricture, of which each was resolved with percutaneous transhepatic biliary drainage and stent insertion. At the last two episodes of cholangitis, stricture of HJ site was found and the patient underwent endoscopic ultrasonography (EUS)-guided balloon dilata- tion followed by $\mathrm{HJ}$ stent insertion (Fig. 3).

On follow-up examination at postoperative 16 years, a mass within the pancreas head was identified on CT scan (Fig. 4). The mass was identified as adenocarcinoma on EUS-guided fine needle aspiration biopsy.

Thus pylorus-preserving pancreatoduodenectomy was performed. Pathologic examination showed a $3.5 \mathrm{~cm}$-sized 
moderately differentiated adenocarcinoma arising from the remnant $\mathrm{CC}$, with no lymph node metastasis (Fig. 5).

The patient recovered uneventfully and is currently undergoing adjuvant chemotherapy (Fig. 6).

\section{DISCUSSION}

$\mathrm{CC}$ excision with HJ have been the mainstay of the management of $\mathrm{CC}$. However, some problems remain with the intrahepatic and distal end part of the CC. Although radical cyst excision is well known to be the treatment of choice, due to the morbidity of porta hepatis dissection and postoperative complications such as pancreatic fistula and pancreatitis, surgeons are occasionally reluctant to perform aggressive complete excision. ${ }^{3}$

However, it is constantly reported that the remnant CC went manifested malignant transformation indicating the need for life-long follow-up after the surgery. In a Chinese study that included 78 patients with partial resection of

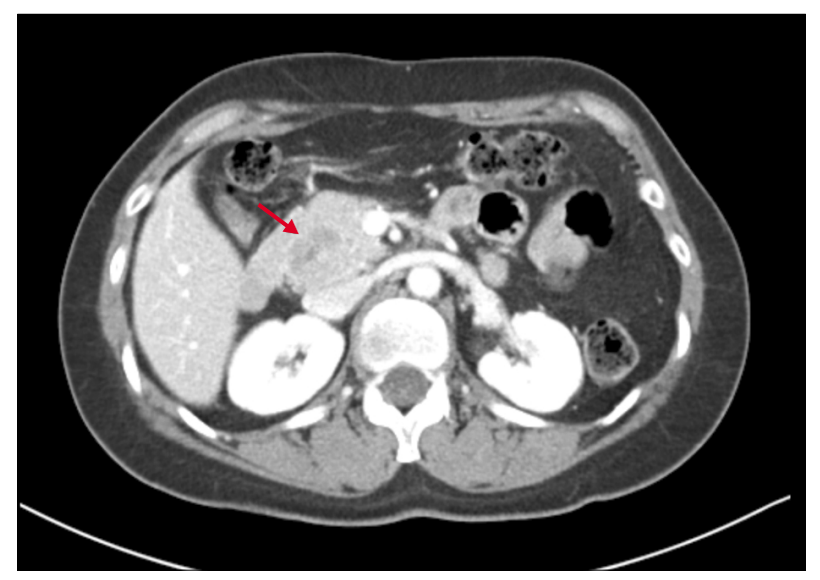

Fig. 4. Computed tomography taken 16 years after choledochal cyst excision reveals a $3.0 \mathrm{~cm}$-sized mass (arrow) arising from the remnant intrapancreatic choledochal cyst without significant pancreatic duct dilatation. the $\mathrm{CC}$, the patients developed associated symptoms, including new cyst, calculus of the bile duct (65.4\%), and carcinogenesis $(14.1 \%)$ in the residual intrapancreatic biliary duct. The authors concluded that surgical re-excision should be considered in patients with a residual intrapancreatic portion of the $\mathrm{CC}$ due to prior incomplete surgery, regardless of clinical symptoms. ${ }^{1}$

The actual size of a residual intrapancreatic portion of the $\mathrm{CC}$ is initially estimated in the first postoperative CT scan and more accurately assessed with magnetic resonance cholangiopancreatography (MRCP). ${ }^{4}$ Preoperative MRCP examination is also essential to avoid damaging the pancreatic duct during surgery because it can visualize specific morphology of the pancreatobiliary duct junction. ${ }^{5}$

Development of cholangiocarcinoma more than 10 years after excision of $\mathrm{CC}$ is rare, with less than 21 cases reported in literature from 1972 to 2014 with a median period of recurrence at 6 years (range 2-34 years). ${ }^{6-21}$

Various theories have been proposed to explain development of malignancy in patients with previously resected

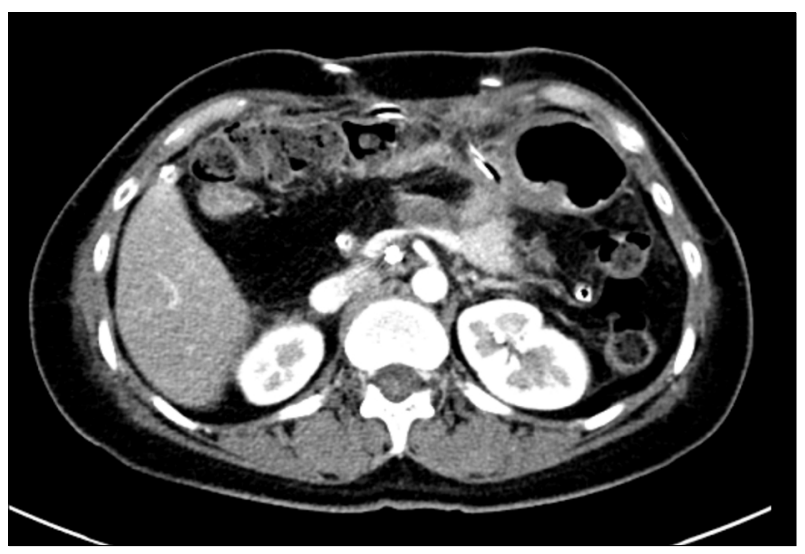

Fig. 6. Follow-up computed tomography at 2 weeks after pancreatoduodenectomy with extended pancreatic transection shows no unusual findings.
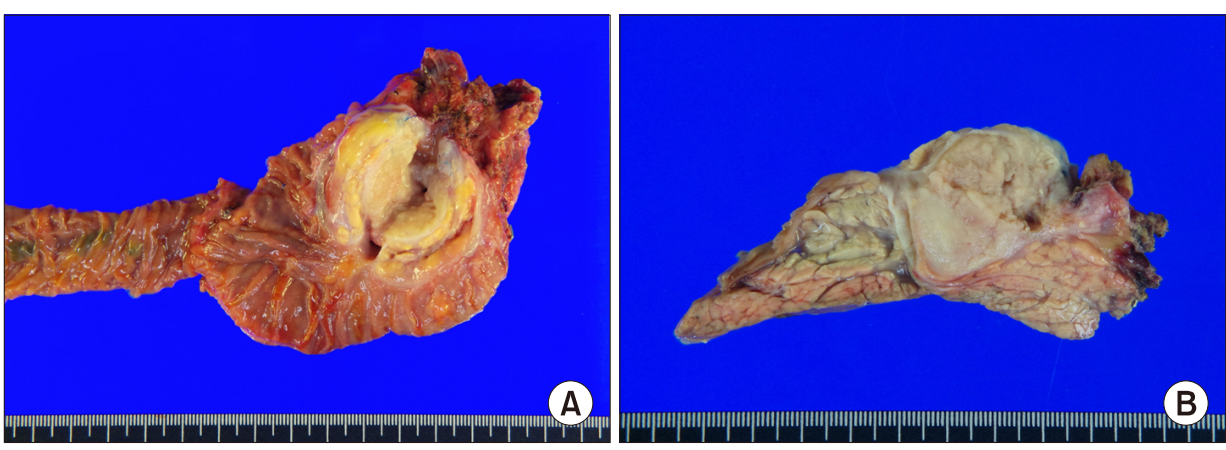

Fig. 5. Gross photographs of the resected specimen after pancreatoduodenectomy. (A) A mass is located at the remnant choledochal cyst portion. (B) A moderately differentiated nodulartype cholangiocarcinoma of 3.5 $\mathrm{cm} \times 2.7 \mathrm{~cm} \times 1.9 \mathrm{~cm}$, was diagnosed with no metastasis in 15 lymph nodes. 
CC. First, it was suggested that the epithelium of the remnant bile duct wall is already at a precancerous stage at the time of surgery and hence, development of cholangiocarcinoma is merely a result of carcinogenesis during the postoperative period. ${ }^{7}$ Second, existence of stenosis at the anastomosis or in the intrahepatic bile duct may induce carcinogenesis. Moreover, some have postulated that carcinogenesis is caused by repeated damage of the biliary epithelium by bile fluid as well as bacterial contamination, leading to mucosal metaplasia. ${ }^{8}$ Last, cholangiocarcinoma can develop spontaneously in the general population, which may explain largely variable intervals of presentation of cholangiocarcinoma in these patients.

While the risk of interval malignancy is well known, there are no practical guidelines for the duration of follow-up and the type of investigations that patients should undergo after initial surgery for CC. Most patients diagnosed with cholangiocarcinoma long after resection of CC were not followed up routinely with radiological imaging and tumor markers. ${ }^{6}$ De novo malignancy was detected, only when patients were symptomatic with cholangitis at presentation.

Recently, minimal-invasive surgery for $\mathrm{CC}$ has been performed. $^{22,23}$ While the interval between $\mathrm{CC}$ excision and detection of carcinoma varies from a few years to decades, it's been only several years since the rise of minimal-invasive surgery for CC. Although the short term result of laparoscopic/robotic excision of the CC shows considerable benefits as compared to open excision, the need for complete excision of $\mathrm{CC}$ and the absence of long-term follow-up results of minimal-invasive surgery should never be neglected.

This case indicates that remnant $\mathrm{CC}$ can undergo malignant transformation 16 years after resection of $\mathrm{CC}$. Thus, complete resection of $\mathrm{CC}$, coupled with life-long followup, is emphasized.

\section{REFERENCES}

1. Fan F, Xu DP, Xiong ZX, Li HJ, Xin HB, Zhao H, et al. Clinical significance of intrapancreatic choledochal cyst excision in surgical management of type I choledochal cyst. J Int Med Res 2018; 46:1221-1229.

2. Cho MJ, Hwang S, Lee YJ, Kim KH, Ahn CS, Moon DB, et al. Surgical experience of 204 cases of adult choledochal cyst disease over 14 years. World J Surg 2011;35:1094-1102.

3. Ando H, Kaneko K, Ito T, Watanabe Y, Seo T, Harada T, et al.
Complete excision of the intrapancreatic portion of choledochal cysts. J Am Coll Surg 1996;183:317-321.

4. Shimizu T, Suzuki R, Yamashiro Y, Segawa O, Yamataka A, Kuwatsuru R. Magnetic resonance cholangiopancreatography in assessing the cause of acute pancreatitis in children. Pancreas 2001;22:196-199.

5. Yoon JH. Magnetic resonance cholangiopancreatography diagnosis of choledochal cyst involving the cystic duct: report of three cases. Br J Radiol 2011;84:e18-e22.

6. Ng DW, Chiow AK, Poh WT, Tan SS. Metachronous cholangiocarcinoma 13 years post resection of choledochal cyst-is long-term follow-up useful?: a case study and review of the literature. Surg Case Rep 2016;2:60.

7. Shimamura K, Kurosaki I, Sato D, Takano K, Yokoyama N, Sato Y, et al. Intrahepatic cholangiocarcinoma arising 34 years after excision of a type IV-A congenital choledochal cyst: report of a case. Surg Today 2009;39:247-251.

8. Kumamoto T, Tanaka K, Takeda K, Nojiri K, Mori R, Taniguchi $\mathrm{K}$, et al. Intrahepatic cholangiocarcinoma arising 28 years after excision of a type IV-A congenital choledochal cyst: report of a case. Surg Today 2014;444:354-358.

9. Goto N, Yasuda I, Uematsu T, Kanemura N, Takao S, Ando K, et al. Intrahepatic cholangiocarcinoma arising 10 years after the excision of congenital extrahepatic biliary dilation. J Gastroenterol 2001;36:856-862.

10. Nishiyama R, Shinoda M, Tanabe M, Masugi Y, Ueno A, Hibi $\mathrm{T}$, et al. Intrahepatic cholangiocarcinoma arising 33 years after excision of a choledochal cyst: report of a case. Int Surg 2011; 96:320-325.

11. Ohashi T, Wakai T, Kubota M, Matsuda Y, Arai Y, Ohyama $\mathrm{T}$, et al. Risk of subsequent biliary malignancy in patients undergoing cyst excision for congenital choledochal cysts. J Gastroenterol Hepatol 2013;28:243-247.

12. Thistlethwaite JR, Horwitz A. Choledochal cyst followed by carcinoma of the hepatic duct. South Med J 1967;60:872-874.

13. Gallagher PJ, Millis RR, Mitchinson MJ. Congenital dilatation of the intrahepatic bile ducts with cholangiocarcinoma. J Clin Pathol 1972;25:804-808.

14. Chaudhuri PK, Chaudhuri B, Schuler JJ, Nyhus LM. Carcinoma associated with congenital cystic dilation of bile ducts. Arch Surg 1982;117:1349-1351.

15. Yoshikawa K, Yoshida K, Shirai Y, Sato N, Kashima Y, Coutinho DS, et al. A case of carcinoma arising in the intrapancreatic terminal choledochus 12 years after primary excision of a giant choledochal cyst. Am J Gastroenterol 1986;81:378-384.

16. Rossi RL, Silverman ML, Braasch JW, Munson JL, ReMine SG. Carcinomas arising in cystic conditions of the bile ducts. A clinical and pathologic study. Ann Surg 1987;205:377-384.

17. Young WT, Thomas GV, Blethyn AJ, Lawrie BW. Choledochal cyst and congenital anomalies of the pancreatico-biliary junction: the clinical findings, radiology and outcome in nine cases. $\mathrm{Br}$ J Radiol 1992;65:33-38.

18. Kobayashi S, Asano T, Yamasaki M, Kenmochi T, Nakagohri $\mathrm{T}$, Ochiai T. Risk of bile duct carcinogenesis after excision of extrahepatic bile ducts in pancreaticobiliary maljunction. Surgery 1999;126:939-944.

19. Koike M, Yasui K, Shimizu Y, Kodera Y, Hirai T, Morimoto $\mathrm{T}$, et al. Carcinoma of the hepatic hilus developing 21 years after biliary diversion for choledochal cyst: a case report. Hepatogastroenterology 2002;49:1216-1220.

20. Suzuki S, Amano K, Harada N, Tanaka S, Hayashi T, Suzuki $\mathrm{M}$, et al. A case of intrahepatic cholangiocarcinoma arising 26 years after excision of congenital biliary dilatation. Jpn J Gastroenterol Surg 2004;37:416-421. 
21. Ono S, Sakai K, Kimura O, Iwai N. Development of bile duct cancer in a 26-year-old man after resection of infantile choledochal cyst. J Pediatr Surg 2008;43:E17-E19.

22. Han JH, Lee JH, Hwang DW, Song KB, Shin SH, Kwon JW, et al. Robot resection of a choledochal cyst with Roux-en-y hepaticojejunostomy in adults: initial experiences with 22 cases and a comparison with laparoscopic approaches. Ann Hepatobiliary Pancreat Surg 2018;22:359-366.

23. Margonis GA, Spolverato G, Kim Y, Marques H, Poultsides G, Maithel S, et al. Minimally invasive resection of choledochal cyst: a feasible and safe surgical option. J Gastrointest Surg 2015; $19: 858-865$. 